\title{
Análisis espacio temporal de la biología reproductiva y el reclutamiento del molusco bivalvo Anadara tuberculosa en la costa del Paćfico colombiano
}

Spatio-temporal analysis of the reproductive biology and recruitment of the bivalve mollusks Anadara tuberculosa in the Colombian Pacific coast

\section{Carlos H. Lucero-Rincón',2, Jaime R. Cantera K. ${ }^{2}$, Diego L. Gil-Agudelo ${ }^{1,3}$, Oscar Muñoz ${ }^{4}$, Luis A. Zapata ${ }^{5}$, Nancy Cortes $^{6}$, William O. Gualteros ${ }^{1}$ y Alex Manjarres ${ }^{1}$}

\author{
${ }^{1}$ Instituto de Investigaciones Marinas y Costeras 'José Benito Vives de Andreis', INVEMAR, Sede Pacífico-Colombia, Km 17 \\ recta Cali-Palmira-Ciat, Cali, Colombia. carlucer01@yahoo.es \\ ${ }^{2}$ Departamento de Biología, Facultad de Ciencias Naturales y Exactas, Universidad del Valle, Calle 5 No 13-00, Cali, Colombia \\ ${ }^{3}$ Instituto Colombiano del Petróleo, ECOPETROL, Km 7 vía Piedecuesta-Bucaramanga, Santander, Colombia \\ ${ }^{4}$ Unidad Administrativa Especial del Sistema de Parques Nacionales Naturales, UAESPNN, Sanquianga, Colombia \\ ${ }^{5}$ Programa Marino Costero WWF Colombia, Carrera 35 No. 4 A 25, Cali, Colombia \\ ${ }^{6}$ Asociación de Concheras de Nariño, ASCONAR. Tumaco, Colombia
}

\begin{abstract}
The reproductive cycle, recruitment and maturity size of the mangrove cockle Anadara tuberculosa was studied between August 2009 and August 2010 at the 4 departments of the Colombian Pacific coast. Biological samples were collected on three $50 \mathrm{~m}^{2}$ plots of each region following the traditional method of capture. To determine the state of sexual development, monthly macro and microscopy (using standard histological techniques) observations were performed. The reproductive cycle was divided in 4 stages, resting, development, maturity and spawning. Spawning events were evident throughout the study period, with higher reproductive activity between December and March, and a second short event between June and August. The average maturity size $(46.68 \pm 9.29 \mathrm{~mm})$ and mean first maturity size $(43.50 \mathrm{~mm})$ are below the minimum legal size of capture $(50.00 \mathrm{~mm})$ in Colombia. Temporal variation of reproductive activity and recruitment shows no evidence of sexual maturity synchrony in the Colombian Pacific, important for the establishment of management strategies of the resource. Three percent of hermaphroditism was found which is considered protandric due to the imbalance of sex ratio between females and males (2.46:1) and size difference between sexes.
\end{abstract}

Key words: Mangrove cockle, size of sexual maturity, living mass weight, hermaphroditism, sexual synchrony

Resumen.- Se estudió el ciclo reproductivo, reclutamiento y tallas de madurez de la piangua Anadara tuberculosa entre agosto de 2009 y agosto de 2010 en cuatro departamentos de la costa Pacífica colombiana. Se realizaron muestreos biológicos en 3 parcelas de $50 \mathrm{~m}^{2}$ para cada región, siguiendo la metodología tradicional de captura. Para determinar el estado de desarrollo sexual, mensualmente se realizaron observaciones macroscópicas e histología rutinaria. Para el análisis reproductivo se definieron los estados de reposo, desarrollo, madurez y desove. Eventos de desove fueron evidentes durante todo el tiempo de estudio, con mayor actividad reproductiva entre diciembre y marzo, y otro evento corto entre junio y agosto. En términos generales, las tallas medias de madurez sexual $(46,68 \pm 9,29 \mathrm{~mm})$ y de primera madurez $(43,50 \mathrm{~mm})$, están por debajo de la talla mínima legal de captura $(50,00 \mathrm{~mm})$ en Colombia. La variación temporal de la actividad reproductiva y del reclutamiento, muestra que no se presenta una sincronía de madurez sexual evidente en el Pacífico colombiano, lo cual es información importante para establecer estrategias de manejo del recurso. Se presentó el $3 \%$ de hermafroditismo, considerado protándrico, debido a las diferencias en proporción sexual entre hembras y machos $(2,46: 1)$ y a la diferencia de tallas entre sexos.

Palabras clave: Piangua, talla de madurez sexual, rendimiento de carne, hermafroditismo, sincronía sexual

\section{INTRODUCCIÓN}

La piangua Anadara tuberculosa (Sowerby, 1833) es un molusco bivalvo de la familia Arcidae que se encuentra distribuido en la costa Pacífica americana desde Baja California hasta Punta Telégrafo, Piuta, Perú (Alamo \& Valdivieso 1997); su distribución está estrechamente relacionada con los bosques de mangle rojo Rhizophora mangle y Rhizophora racemosa (Squires et al. 1975). En Colombia se extiende desde Punta Ardita, cerca de la frontera con Panamá, hasta la frontera con el Ecuador y está profundamente ligada al consumo tradicional de las 
comunidades afro-descendientes del litoral Pacífico, quienes la han aprovechado ancestralmente ya que es parte de la base alimenticia de sus comunidades (GilAgudelo et al. 2011). En las últimas décadas se ha convertido en fuente de ingresos económicos, constituyéndose en una importante especie comercial de moluscos en la Costa Pacífica colombiana (Squires et al. 1975, Betancourt \& Cantera 1978, Cantera \& Contreras 1978, Espinosa et al. 2010, Gil-Agudelo et al. 2011). Se estima que en el departamento de Nariño (límite con Ecuador), existe extracción de alrededor de 300 millones de pianguas al año con un valor entre USD\$4 y USD\$5 por cada centenar, lo que representa ingresos anuales potenciales de más de USD \$7.000.000 (Zapata \& Caicedo 2007). Sin embargo, la comercialización nacional representa sólo entre 15 y $20 \%$ de la producción total, mientras que el resto de las capturas es transportado al Ecuador (Borda \& Cruz 2004a). Esta alta tasa de explotación conlleva a que las piangüeras (mujeres que se dedican a la extracción de este molusco) reconozcan una disminución de su oferta natural durante las últimas décadas en toda la costa Pacífica colombiana.

Por lo anterior, se hace necesario el conocimiento sobre el comportamiento reproductivo de A. tuberculosa, en una escala espacial y temporal amplia, con el fin de suministrar información científica válida que contribuyan en la toma de decisiones para el manejo de este recurso en Colombia, teniendo en cuenta que los estudios hasta el momento a pesar de su aparente abundancia, ofrecen información puntual, fragmentada en el tiempo y con diferencias metodológicas. A nivel internacional, existen trabajos científicos orientados a mejorar la implementación de las técnicas de acuacultura para las diferentes especies de Anadara tanto en condiciones de laboratorio como en el campo (Broom 1982, 1985, JICA-CENDEPESCA 2007), mientras algunos dirigen sus esfuerzos a entender los comportamientos reproductivos, relación sexual, estados larvales, biología y ecología de A. tuberculosa (Baqueiro \& Stuardo 1977, Cruz 1982, Baqueiro 1984, Fournier \& Cruz 1987, Cruz 1987, Ampie \& Cruz 1989, Campos et al. 1990, Silva \& Bonilla 2001, Ortiz et al. 2003, Pérez-Medina 2005, Flores \& Lincadeo 2010).

En Colombia, se han orientado estudios al entendimiento de aspectos biológico-pesqueros (Squires et al. 1975, Franco 1995, Haskoning 1986, Cruz \& Borda 2003, Borda \& Cruz 2004a, b y c; Espinosa et al. 2010, Lucero et al. 2012), indicando la reducción de las poblaciones y de tallas de captura, mientras otros analizan las estrategias de conservación y acuerdos de manejo conjunto entre autoridades y comunidades (Espinosa et al. 2010, Roldan et al. 2010). Respecto a la biología reproductiva, ésta ha sido abordada por Squires et al. (1975), Herrán (1983), Borda \& Cruz (2004a) y Lucero et al. (2012), sin embargo, persisten dudas sobre el comportamiento reproductivo de la especie debido a que estos estudios han sido espacial y temporalmente puntuales, por lo que se hace necesario encaminar esfuerzos investigativos para proveer de antecedentes y establecer las herramientas necesarias para mejorar las decisiones y el adecuado manejo de la especie. El presente trabajo tuvo como objetivo evaluar el ciclo reproductivo de A. tuberculosa de manera simultánea a lo largo de la costa Pacífica colombiana, para generar información válida en la aplicación de medidas de manejo y aprovechamiento sostenible de la especie en Colombia.

\section{MATERIALES Y MÉTODOS}

Entre agosto de 2009 y agosto de 2010, se realizaron muestreos mensuales de Anadara tuberculosa en 5 localidades de la región Pacífica colombiana, en donde existe alguna dependencia de este recurso por parte de las comunidades locales. Las localidades fueron Tumaco $\left(01^{\circ} 48^{\prime} 54.4^{\prime \prime} \mathrm{N}\right.$; $\left.078^{\circ} 48^{\prime} 27,5^{\prime \prime} \mathrm{W}\right)$ y Amarales $\left(02^{\circ} 37^{\prime} 47^{\prime \prime} \mathrm{N}\right.$; $078^{\circ} 11^{\prime} 20^{\prime \prime} \mathrm{W}$ ) en el departamento de Nariño, Cuerval $\left(02^{\circ} 45^{\prime} 08,5^{\prime \prime} \mathrm{N}\right.$; $\left.077^{\circ} 47^{\prime} 01,5^{\prime \prime} \mathrm{W}\right)$ en el departamento del

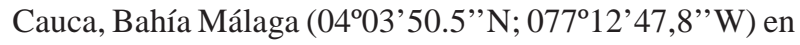
el departamento del Valle del Cauca y Pizarro $\left(04^{\circ} 50^{\prime} 24,9^{\prime \prime} \mathrm{N}\right.$; $\left.077^{\circ} 20^{\prime} 38,5^{\prime \prime} \mathrm{W}\right)$ en el departamento del Chocó (Fig. 1).

Las capturas de A. tuberculosa fueron realizadas siguiendo el método de recolección manual tradicional (Espinosa et al. 2010), utilizando 4 personas expertas, por un tiempo estándar de $1 \mathrm{~h}$ en cada una de las 3 parcelas de $100 \mathrm{~m}^{2}$ delimitadas aleatoriamente en cada zona de estudio (Lucero et al. 2012). Para la observación macroscópica y microscópica del tejido reproductivo vivo se seleccionaron 100 individuos, mientras que para histología fueron seleccionados 20 de las diferentes clases de tallas cada mes en cada una de las 5 áreas estudiadas. En total, 5.381 individuos fueron analizados para determinar el desarrollo sexual de esta especie a lo largo del Pacífico colombiano.

Para la observación macroscópica de los individuos, se separó la carne de la concha y se realizó un corte transversal para conocer el color, ubicación y distribución de la gónada. Cuando no fue posible observar la gónada o parte de ella, se realiza un segundo corte longitudinal 


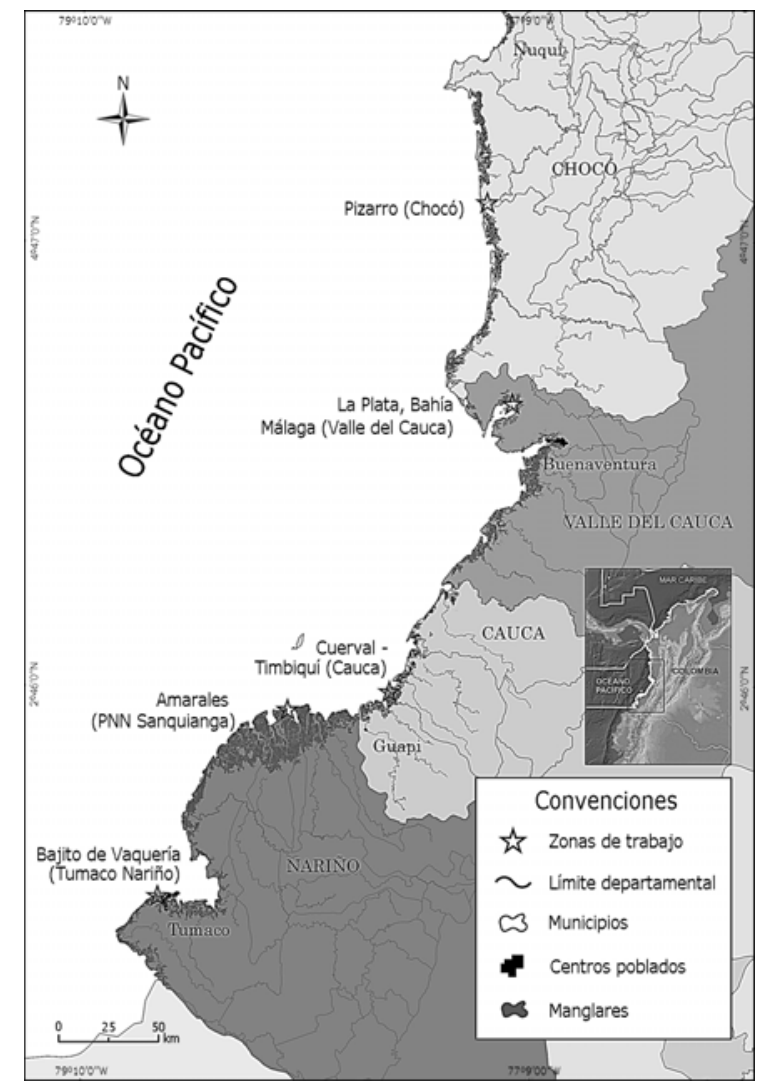

Figura 1. Localización de las zonas de estudio en la costa del Pacífico colombiano / Area of study in the Pacific coast of Colombia

medio desde la región más próxima al músculo aductor anterior hasta el músculo aductor posterior, lo que hace posible observar la gónada cuando no se encuentra en estadios avanzados. Esto permitió estimar por observación directa, una aproximación del porcentaje ocupado de la gónada dentro de la cavidad visceral, para clasificar los estadios en reposo o desove, desarrollo y madurez. Se anotó la coloración de la gónada, anaranjada en hembras y crema o blanca en machos. Para la observación macroscópica se estimó el volumen de la gónada y su porcentaje con respecto a la ocupación de la cavidad visceral y se anotó la coloración de hembras y machos.

Mediante observaciones microscópicas de frotis e histología de las gónadas (Herrán 1983, Ampie \& Cruz 1988, García-Domínguez et al. 2008), se determinó el estado de desarrollo sexual de cada individuo y las épocas de los máximos reproductivos basándose en las guías y descripciones de Kenneth (1969), Narchi (1976), Baqueiro \& Stuardo (1977), Herrán (1983), Cruz (1984), Ampie \& Cruz (1989), García-Domínguez et al. (2008) y Lucero et al. (2012). Se realizaron descripciones adicionales y se guardaron registros fotográficos de las placas. Se calculó el índice de madurez sexual (IMS) para cada mes, el cual relaciona el número de individuos maduros con el número total de hembras analizadas.

Debido a la dificultad de separar la masa somática de la masa reproductiva ya que el tejido reproductivo se encuentra fusionado con la masa visceral, se utilizó el índice de condición expresado como rendimiento de carne para complementar el análisis reproductivo de $A$. tuberculosa. Este índice ofrece la ventaja de ser una medida cuantitativa que se puede estimar fácil y objetivamente. El rendimiento de la carne (R), se define como la capacidad del animal para producir la máxima cantidad de carne (Cruz 1984) y es un índice de condición que funciona como medida que refleja la actividad fisiológica del organismo en diferentes condiciones ambientales. Este se calcula considerando el peso fresco de la carne en relación con el peso total (Cruz \& Palacios 1983). Para establecer diferencias de este índice entre las zonas de estudio y entre las tallas evaluadas, se realizó una prueba no paramétrica de Kruskal-Wallis para un 95\% 
de confianza. Las tallas se agruparon arbitrariamente en 4 grupos: mayores a $50 \mathrm{~mm}$, entre $40 \mathrm{~mm}$ y $50 \mathrm{~mm}$, entre 30 mm y $40 \mathrm{~mm}$ y menores de $30 \mathrm{~mm}$.

Se determinó la talla media donde el 50\% de la población de A. tuberculosa ha tenido al menos un desove $\left(\mathrm{Lt}_{50 \%}\right)$, siendo está considerada como la talla media de la primera madurez sexual (TMPM) (Borda \& Cruz 2004a). Para esto se usó la evaluación de las composiciones por tallas, utilizando la metodología descrita por Tresierra \& Culquichicón (1995). Se realizó un gráfico (ojiva suavizada) de distribución de frecuencias para variables continuas con base en la longitud de la concha, para lo que se usaron los individuos maduros. La longitud en donde corte la curva en el $50 \%$ de las frecuencias acumuladas, fue considerada la talla media donde por lo menos el $50 \%$ de la población ha tenido mínimo un desove $\left(\mathrm{Lt}_{50 \%}\right)$. La talla media de madurez mensual (TMM), se obtuvo con un intervalo de confianza al 95\% (Jiménez 1988), así:

$$
\begin{gathered}
\operatorname{TMM}_{i}=\frac{1}{n} \sum_{j=1}^{m} F(j) \bar{L}(j) \\
S^{2}=\frac{1}{n-1} \sum_{j=1}^{m} F(j)[\bar{L}(j)-T M M]^{2}
\end{gathered}
$$

donde $n$ es el tamaño de la muestra, m es el número de grupos de longitud, $j$ el número de intervalo, F la frecuencia observada, es la marca de clase y $\mathrm{S}^{2}$ es la varianza.

Debido a que la estimación es diferente de la media verdadera de la población, la incertidumbre acerca de la media verdadera se expresó con los límites de confianza. Para el caso de la distribución normal, estos límites están dados por:

$$
T M M \pm t_{n-1}(s / \sqrt{n)}
$$

Tabla 1. Comparación de los estados de desarrollo sexual de acuerdo a las observaciones macroscópicas y microscópicas de la piangua Anadara tuberculosa en el Pacífico colombiano. Descripciones modificadas de Herrán (1984) y Lucero et al. (2012) / Comparison of sexual development stages of Anadara tuberculosa

\begin{tabular}{|c|c|c|c|}
\hline Observación macroscópica & Características macroscópicas & Observación microscópica & Características microscópicas \\
\hline Reposo & Glándula no visible & Indiferenciación & Ausencia de gametos \\
\hline Desarrollo/Inmaduro & $\begin{array}{l}\text { La glándula es acinosa, } \\
\text { blanda y reducida. Glándula } \\
\text { pequeña limitando con el } \\
\text { endodermo. Color naranja } \\
\text { claro si es hembra y color } \\
\text { crema si es macho. Volumen } \\
\text { de la gónada menos del } 50 \% \\
\text { de la masa visceral. }\end{array}$ & $\begin{array}{l}\text { Previtelogénesis, } \\
\text { Gametogénesis inicial }\end{array}$ & $\begin{array}{l}\text { Folículos ováricos y túbulos seminiferos } \\
\text { escasos, con mucha luz al interior. Células } \\
\text { sexuales escasas. Presencia en hembras de } \\
\text { oogonias sin núcleo, oocitos primarios con } \\
\text { núcleo poco definido y oocitos secundarios } \\
\text { piriformes. En los machos hay presencia de } \\
\text { espermatogonias y espermatocitos primarios } \\
\text { como células redondas y núcleo central. }\end{array}$ \\
\hline Madurez inicial & $\begin{array}{l}\text { Glándula más abundante y de } \\
\text { consistencia intermedia. Inter- } \\
\text { visceralmente entre el hepato- } \\
\text { páncreas y el estómago, } \\
\text { gónada color naranja si es } \\
\text { hembra y color crema o } \\
\text { blanco si es macho. Más del } \\
50 \% \text { de la masa visceral. En } \\
\text { ocasiones no se diferencia de } \\
\text { la etapa siguiente. }\end{array}$ & $\begin{array}{l}\text { Vitelogénesis, } \\
\text { Gametogénesis avanzada }\end{array}$ & $\begin{array}{l}\text { Folículos ováricos y túbulos seminiferos } \\
\text { abundantes. Algunas células con divisiones } \\
\text { mitóticas, oocitos secundarios piriformes } \\
\text { adheridos a la pared folicular y óvulos con } \\
\text { nácelo, nucléolo y membrana nuclear } \\
\text { definida. En machos, los espermatocitos } \\
\text { secundarios son esféricos y algunos } \\
\text { tetraédricos, pobres en citoplasma, con } \\
\text { divisiones meióticas previas a la maduración. } \\
\text { El núcleo es central y algunos son periféricos. }\end{array}$ \\
\hline Madurez & $\begin{array}{l}\text { Glándula abundante, turgente } \\
\text { y dura. Se extiende por toda la } \\
\text { superficie ventral, y dorsal- } \\
\text { mente hasta el saco peri- } \\
\text { cardial, anteriormente hasta el } \\
\text { músculo aductor anterior y } \\
\text { posteriormente hasta el límite } \\
\text { con el músculo del pie. } \\
\text { Volumen más del } 80 \% \text { de la } \\
\text { masa visceral. }\end{array}$ & Madurez & $\begin{array}{l}\text { Folículos ováricos y túbulos seminiferos muy } \\
\text { abundantes y poca luz, con óvulos y } \\
\text { espermatozoides abundantes en su interior. } \\
\text { Óvulos con núcleo central bien definido por } \\
\text { membrana nuclear y nucléolo periférico listo } \\
\text { para atravesar la membrana nuclear. Gran } \\
\text { cantidad de espermatozoides dirigidos hacia } \\
\text { el centro del túbulo. Escasos gránulos de } \\
\text { secreción y tejido conectivo interfolicular. }\end{array}$ \\
\hline Desove & $\begin{array}{l}\text { Similar al estado de desa- } \\
\text { rrollo, y puede ser confun- } \\
\text { dido como inmaduro, pero se } \\
\text { distingue por la flacidez de la } \\
\text { gónada y la presencia de } \\
\text { manchas café y rojas. }\end{array}$ & Desove/emisión de gametos & $\begin{array}{l}\text { Folículos ováricos y túbulos seminiferos } \\
\text { flácidos, alargados o comprimidos, con pocas } \\
\text { células sexuales, gran cantidad de glóbulos } \\
\text { rojos, gránulos de secreción de color café y } \\
\text { tejido conectivo interfolicular de color azul. } \\
\text { Hay deformación del citoplasma, con el } \\
\text { rompimiento de la membrana nuclear. } \\
\text { Presencia de algunas células amorfas. }\end{array}$ \\
\hline
\end{tabular}
according to macroscopic and microscopic observations in the Pacific coast of Colombia. Descriptions modified from Herran (1984) and Lucero et al. (2012) 
donde $s$, es la desviación estándar y $t_{\mathrm{n}-1}$ son los llamados percentiles de la distribución (Jiménez 1988).

La variación de las tallas de madurez entre las zonas de estudio fue comparada con la aplicación la prueba no paramétrica de Kruskal-Wallis (Zar 1999). Mediante la rutina contenida en FISAT II, se reconstruye los patrones de reclutamiento de una serie temporal de datos de frecuencia de talla para determinar el número de reclutamientos fuertes por año. Este modelo se basa en que todos los individuos de la muestra crecen según lo descrito por un único conjunto de parámetros de crecimiento y un mes fuera de los doce siempre tiene cero de reclutamiento. Se realizó la descomposición de datos para encontrar los patrones característicos de reclutamiento en el año cuando se observaron distribuciones bimodales, para ello se aplicó el enfoque de NORMSEP contenido en las rutinas de FISAT II (Gayanilo et al. 2005).

\section{Resultados}

\section{ANÁLISIS REPRODUCTIVo}

Las observaciones macroscópicas y microscópicas del tejido reproductivo de $A$. tuberculosa, permitieron determinar las características morfológicas de los estados de desarrollo sexual. En base a lo anterior se definieron 5 estados de desarrollo sexual a nivel macroscópico y 5 a nivel microscópico (Tabla 1). La creación de la guía macroscópica, basada en los niveles macroscópicos de volumen y coloración de las gónadas, permite el monitoreo de los eventos reproductivos de A. tuberculosa por parte de personal de las comunidades locales previamente entrenado, lo cual es un importante aporte para adelantar estudios y monitoreo de medidas de manejo local en las regiones del Pacífico colombiano. (Fig. 2). Por su parte, la identificación microscópica de los estadios sexuales se fundamenta en la forma, tamaño y abundancia de las células sexuales, además de la presencia de gránulos de secreción y tejido conectivo (Fig. 3).
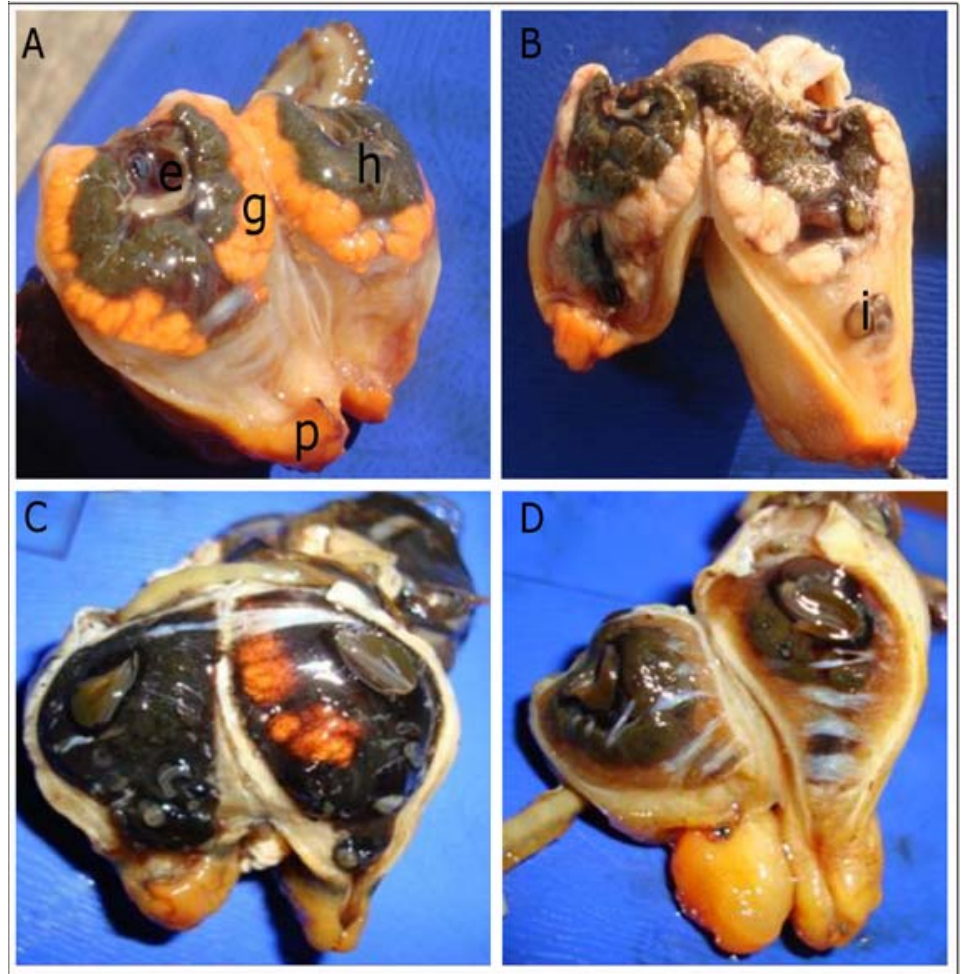

Figura 2. Vista en corte transversal para observación macroscópica de coloración y forma de la gónada en individuos maduros de Anadara tuberculosa. A) Hembra en madurez; B) Macho en madurez, C) Hembra en desarrollo o desove, D) Reposo o indiferenciado. p: Pie; e: Estómago; g: Gónada; i: Intestino; h: Hepatopáncreas / Crossed-section view for macroscopic observation of color and shape of gonads in mature individuals of Anadara tuberculosa. A) Mature female, B) Mature male, C) Female under development or spawning, D) Resting or undifferentiated. p: Foot, e: Stomach; g: Gonad, i: Intestine, h: Hepatopancreas 
La actividad reproductiva en las localidades estudiadas fue la siguiente (Fig. 4):

Tumaco-Nariño: La actividad sexual de A. tuberculosa en el área de Tumaco fue alta y continua durante todo el año, registrándose en 8 de los 13 meses analizados con altos índices de madurez sexual (superior al 50\%). La mayor actividad reproductiva se presentó en junio del 2010, mientras que la menor fue en octubre del 2009. Una temporada reproductiva importante se presenta en la zona entre los meses de diciembre y agosto con pequeños eventos de desove en febrero y mayo. Las mayores épocas de desove son septiembre, octubre y noviembre, con valores que oscilan entre 65 y $79 \%$ de la población desovante.
Amarales (PNN-Sanquianga)-Nariño: Durante el tiempo de estudio se encontró bajos índices de madurez sexual. Sólo se registraron marzo y septiembre como los periodos reproductivo más importantes, los demás meses presentaron fuertes desoves durante todo el año, con valores entre el 70 y $100 \%$.

Cuerval-Cauca: Durante el tiempo de estudio se encontró la mayor parte de individuos en avanzado estado de madurez sexual con pequeños eventos de desove, siendo más fuertes en noviembre y abril (55 y 57\% respectivamente). Se encontraron 2 periodos con mayor porcentaje de individuos sexualmente maduros para la zona, el primero entre diciembre y marzo y el segundo entre mayo y agosto.

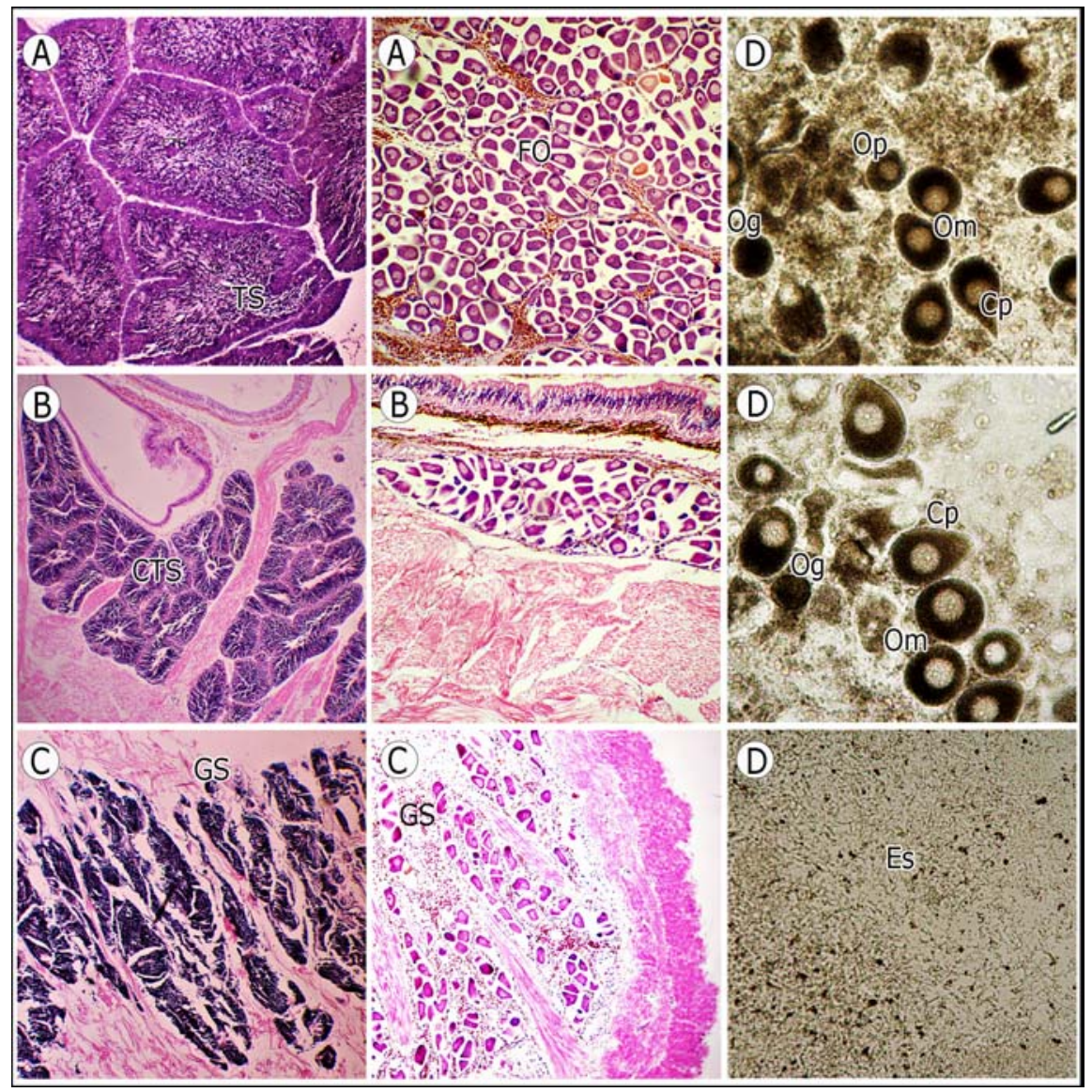

Figura 3. Observación microscópica de madurez sexual a partir de placas histológicas de la piangua Anadara tuberculosa en el Pacífico colombiano. Columna de la izquierda: machos; columna central: hembras. A) Madurez, B) Gametogénesis, C) Desove. TS: Túbulos seminíferos, FO: Folículos ováricos, GS: Gránulos de secreción, CTS: Centro del Túbulo seminífero. D) Frotis del tejido reproductivo vivo. Og: Oogonias, Op: Oocitos primarios, $\mathrm{Cp}$ : Células piriformes (oocitos secundarios), Om: Óvulos maduros con nucléolo periférico, Es: Espermatozoides. Observación bajo objetivo 10x / Microscopic observation using histology techniques of sexual maturity of the mangrove cockle Anadara tuberculosa in the Pacific coast of Colombia. Left column: males, middle column: females. A) Mature, B) Gametogenesis, C) Spawning. TS: Seminiferous tubules, FO: Ovarian follicles, GS: Secretory granules, CTS: Center of the seminiferous tubule. D) Fresh spread of reproductive tissue. Og: Oogonia, Op: Primary oocytes, Cp: pyriform cells (secondary oocytes), Om: mature eggs with peripheral nucleolus, Es: Sperm. Observations under 10x objective 


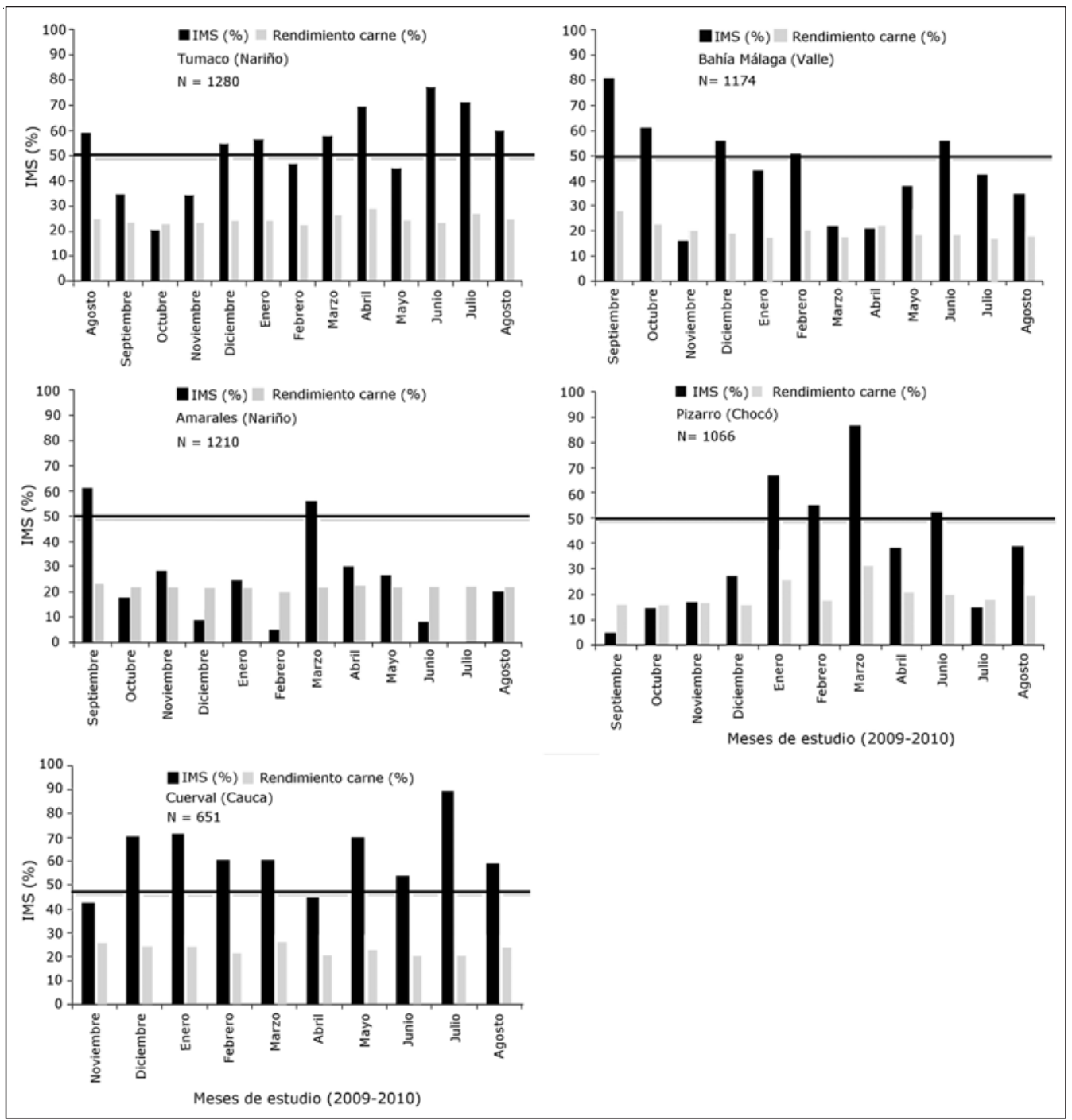

Figura 4. Variación temporal del índice de madurez sexual (IMS) y el rendimiento de carne de Anadara tuberculosa en el Pacífico colombiano / Temporal variation of sexual maturity index (IMS) and the live mass weight of Anadara tuberculosa in the Pacific coast of Colombia

Bahía Málaga-Valle del Cauca: La mayor actividad reproductiva se registró en septiembre, mientras que la menor fue en noviembre. Se encontraron 3 periodos reproductivos importantes para la zona: el de mayor intensidad, se presenta entre septiembre y octubre, el segundo está entre diciembre y febrero y un tercero en junio. Después del primer periodo reproductivo alto, se registra el mayor desove del año en noviembre (84\%) y luego desoves intermedios en enero, marzo y abril. (79\%), mayo y agosto (62 y $65 \%$ respectivamente).

Pizarro-Choco: La temporada reproductiva importante en la zona se presentó entre diciembre y febrero, luego una de menor intensidad en junio; posterior a ello, el desove es fuerte. En esta región, se presenta una temporada de desove larga e intensa con valores entre el $70 \%$ y $95 \%$ de población desovante. Estos meses corresponden a la temporada entre abril y diciembre.

\section{RENDIMIENTO DE CARNE}

El análisis de Kruskal-Wallis para la comparación de los 4 grupos de tallas con el rendimiento de carne, mostró que los grupos de talla 3 y 4 presentan similitud entre sí pero diferencias con los demás $\mathrm{H}_{(4, \mathrm{n}=5260)}=296,6274 ; P<0,05$. Los resultados indican que el rendimiento disminuye con el aumento de tallas (Tabla 2). 
Tabla 2. Variación del rendimiento de carne (\%) entre las zonas del estudio (LI: límite inferior, LS: límite superior) / Variation the live mass weight (\%) among the areas of study (LI: lower limit, LS: upper limit)

\begin{tabular}{lcccc}
\hline \multirow{2}{*}{ Zona de estudio } & Media (\%) & $\begin{array}{l}\text { Desviación } \\
\text { estándar (\%) }\end{array}$ & \multicolumn{2}{c}{ Intervalo de confianza (95\%) } \\
\hline Tumaco & 25,25 & 8,07 & 25,72 & LI \\
Amarales & 21,86 & 4,76 & 22,11 & 21,78 \\
Cuerval & 22,81 & 6,70 & 23,36 & 22,26 \\
Málaga & 20,19 & 7,78 & 20,61 & 19,77 \\
Pizarro & 19,27 & 8,34 & 25,72 & 24,78 \\
\hline
\end{tabular}

Tabla 3. Rendimiento de carne por grupos de tallas de Anadara tuberculosa en el área de estudio (LI: límite inferior, LS: límite superior) / Live mass weight by size groups of Anadara tuberculosa in area of study (LI: lower limit, LS: upper limit)

\begin{tabular}{|c|c|c|c|c|c|c|c|}
\hline \multirow{2}{*}{\multicolumn{2}{|c|}{$\begin{array}{l}\text { Tallas } \\
(\mathrm{mm})\end{array}$}} & \multirow{2}{*}{$\begin{array}{c}\text { Promedio } \\
(\%)\end{array}$} & \multirow{2}{*}{$\begin{array}{c}\text { Desviación } \\
\text { estándar (\%) }\end{array}$} & \multirow{2}{*}{$\begin{array}{c}\text { Error } \\
\text { estándar }\end{array}$} & Intervalo de & Confianza $95 \%$ & \multirow[t]{2}{*}{$\mathbf{n}$} \\
\hline & & & & & LI & LS & \\
\hline 1 & $>50$ & 20,68 & 8,97 & 0,22 & 20,24 & 21,12 & 1616 \\
\hline 2 & $40-50$ & 21,64 & 5,14 & 0,10 & 21,45 & 21,84 & 2663 \\
\hline 3 & $30-40$ & 24,86 & 14,12 & 0,48 & 23,93 & 25,80 & 884 \\
\hline 4 & $<30$ & 24,66 & 8,86 & 0,90 & 22,87 & 26,46 & 96 \\
\hline & Promedio & 21,95 & 8,66 & 0,12 & 21,71 & 22,18 & 5260 \\
\hline
\end{tabular}

En términos generales el rendimiento medio de carne en la costa del Pacífico colombiano fue de 21,91\% $\pm 7,44 \%$ (IC ${ }_{95 \%}: 21,71-22,11 \%$ ). Se presentó una alta variación entre las zonas estudiadas, con diferencias significativas entre ellas $\left(\mathrm{H}_{(4, \mathrm{n}=5260)}=1080,678 ; P<0,05\right)$. Durante el tiempo de estudio, Tumaco registró el rendimiento promedio más alto $(25,25 \pm 8,07)$, mientras que Pizarro el más bajo $(19,27$ $\pm 8,34$ ) (Tabla 3) durante el tiempo de estudio.

Cuatro de las 5 zonas evaluadas presentaron correlaciones positivas altas en cuanto al rendimiento de carne y madurez sexual, exceptuando Cuerval. En Pizarro se obtuvo la mayor correlación ( $r=0,78)$, en bahía Málaga fue de 0,51 y en Tumaco y Amarales se registró 0,60, mostrando que los meses de mayor actividad reproductiva coinciden con los de mayor rendimiento de carne (Fig. 5).

\section{ANÁLISIS DE TALLAS y RECLUTAMIENTO}

La prueba no paramétrica de Kruskal-Wallis, mostró diferencias significativas de la talla media de madurez sexual entre las zonas de estudio $\left(\mathrm{H}_{(4,2353)}=283,76 ; P<\right.$ $0,05)$, sin embargo los registros más bajos encontrados en Tumaco y Bahía Málaga muestran similitud en sus tallas medias $(P>0,05)$, así como los más altos en Amarales y Pizarro $(P>0,05)$, pero entre estos grupos hay diferencia (Tabla 4).
Tabla 4. Comparación de las tallas medias $(\mathrm{mm})$ de madurez sexual de Anadara tuberculosa en el Pacífico colombiano (LI: límite inferior, LS: límite superior) / Comparison of mean sexual maturity length $(\mathrm{mm})$ of Anadara tuberculosa in the Pacific coast of Colombia (LI: lower limit, LS: upper limit)

\begin{tabular}{|c|c|c|c|c|c|}
\hline \multirow{2}{*}{ Localidad } & \multirow[b]{2}{*}{ Media } & \multirow{2}{*}{$\begin{array}{c}\text { Error } \\
\text { estándar }\end{array}$} & \multicolumn{2}{|c|}{ Intervalo de confianza (95\%) } & \multirow[b]{2}{*}{$\mathbf{n}$} \\
\hline & & & LI & LS & \\
\hline Tumaco & 43,35 & 0,28 & 42,80 & 43,90 & 684 \\
\hline Amarales & 49,61 & 0,41 & 48,81 & 50,41 & 319 \\
\hline Cuerval & 46,13 & 0,37 & 45,40 & 46,86 & 383 \\
\hline Málaga & 44,67 & 0,31 & 44,06 & 45,27 & 555 \\
\hline Pizarro & 49,70 & 0,36 & 48,00 & 50,41 & 412 \\
\hline Promedio & 46,07 & 0,16 & 45,76 & 46,39 & 2353 \\
\hline
\end{tabular}

De acuerdo a la talla mínima de madurez sexual, para Tumaco resultó 20,18 mm, mientras que en Pizarro fue de 30,74 mm. Amarales, Cuerval y Bahía Málaga, registraron tallas de mínima madurez intermedias entre estas $(22,61$ $\mathrm{mm}, 23,04 \mathrm{~mm}$ y 26,90 $\mathrm{mm}$ respectivamente). Tumaco no presenta diferencias significativas de tallas medias entre sexo $(P>0,05)$, mientras que las demás localidades si $(P<$ $0,05)$. Los resultados indican que a diferencia de Tumaco, en las demás regiones de estudio, las hembras de Anadara tuberculosa generalmente son de mayor longitud y abundancia que los machos (Tabla 5).

La talla media en la que el 50\% de la población de $A$. tuberculosa tuvo al menos un desove (TMPM), en el Pacífico colombiano, fue de $43,50 \mathrm{~mm}$, con variaciones importantes en cada una de las localidades objeto de estudio; Tumaco (41,00 mm) y Bahía Málaga (42,30 mm) registraron los más bajos, Cuerval $(44,10 \mathrm{~mm})$ tallas intermedias, mientras que Amarales (46,40 mm) y Pizarro (47,40 mm) los más altos (Fig. 5).

Un fuerte máximo de reclutamiento se presentó en Tumaco y Bahía Málaga con un 24 y 23\% en abril y marzo respectivamente, mientras que en las demás zonas estudiadas el patrón de reclutamiento se presentó durante el segundo semestre del año, especialmente entre junio y septiembre. Los meses de mayor reclutamiento en las zonas corresponden a junio y septiembre (13\%) en Amarales, junio (18,66\%) y agosto (16\%) en Cuerval y agosto (19,05\%) en Pizarro (Fig. 6). Aunque la mayoría de las zonas muestran un patrón bimodal de reclutamiento anual, en Pizarro es unimodal, en la segunda mitad del año. 

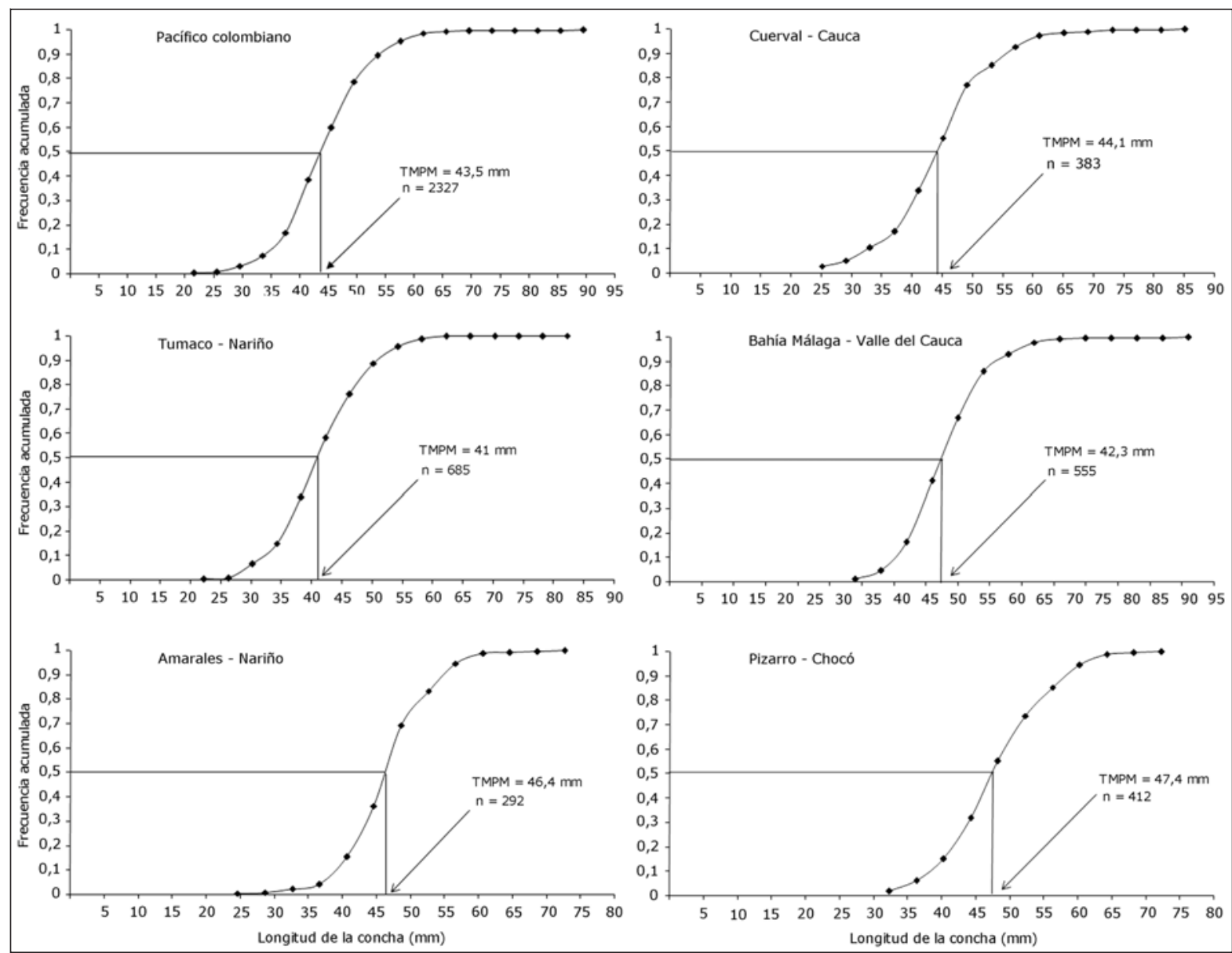

Figura 5. Talla media de la primera madurez sexual (TMPM) de la piangua Anadara tuberculosa en 2009 y 2010 en el Pacífico colombiano / Average size of first maturity (TMPM) of Anadara tuberculosa in 2009 and 2010 in the Pacific coast of Colombia

Tabla. 5. Comparación de las abundancias y tallas medias $(\mathrm{mm})$ por sexo de Anadara tuberculosa en el Pacífico colombiano / Comparison of abundance and mean lengths $(\mathrm{mm})$ by sex of Anadara tuberculosa in the Pacific coast of Colombia

\begin{tabular}{lcccccccc}
\hline & \multicolumn{3}{c}{ Hembras } & & \multicolumn{3}{c}{ Machos } \\
\cline { 2 - 5 } \cline { 7 - 8 } Localidad & $\mathrm{n}$ & Media & $\begin{array}{c}\text { Desviación } \\
\text { estándar }\end{array}$ & & $\mathrm{n}$ & Media & $\begin{array}{c}\text { Desviación } \\
\text { estándar }\end{array}$ \\
\hline Tumaco & 754 & 42,63 & 7,36 & & 391 & 42.88 & 6,71 \\
Amarales & 674 & 48,61 & 6,63 & & 372 & 46.94 & 8,79 \\
Cuerval & 399 & 47,38 & 8,78 & & 152 & 44,08 & 8,74 \\
Málaga & 820 & 45,69 & 6,53 & & 222 & 44,02 & 7,30 \\
Pizarro & 607 & 50,40 & 7,16 & & 175 & 49,51 & 7,47 \\
Promedio & 3254 & 46,67 & 7,29 & & 1312 & 45,25 & 7,81 \\
\hline
\end{tabular}

\section{Discusión}

Los resultados indican que no se presenta una sincronía de madurez sexual de la piangua Anadara tuberculosa en las localidades estudiadas en el Pacífico colombiano, lo cual está relacionado con las características de la especie estudiada, con las variaciones ambientales y otros factores no especificados en este estudio. Sin embargo, existe una tendencia de presentar mayores índices de madurez sexual entre diciembre y marzo, y menor en junio. Los desoves más importantes son en noviembre. La mayor actividad de desove se presenta en el segundo semestre del año, lo cual coincide con lo expuesto por Borda \& Cruz (2004) para Tumaco. Durante todos los muestreos se encontraron individuos maduros con desoves simultáneos cada mes, lo cual garantiza la presencia potencial de larvas y juveniles durante todo el año. Estas diferencias halladas deben ser consideradas para la implementación de 


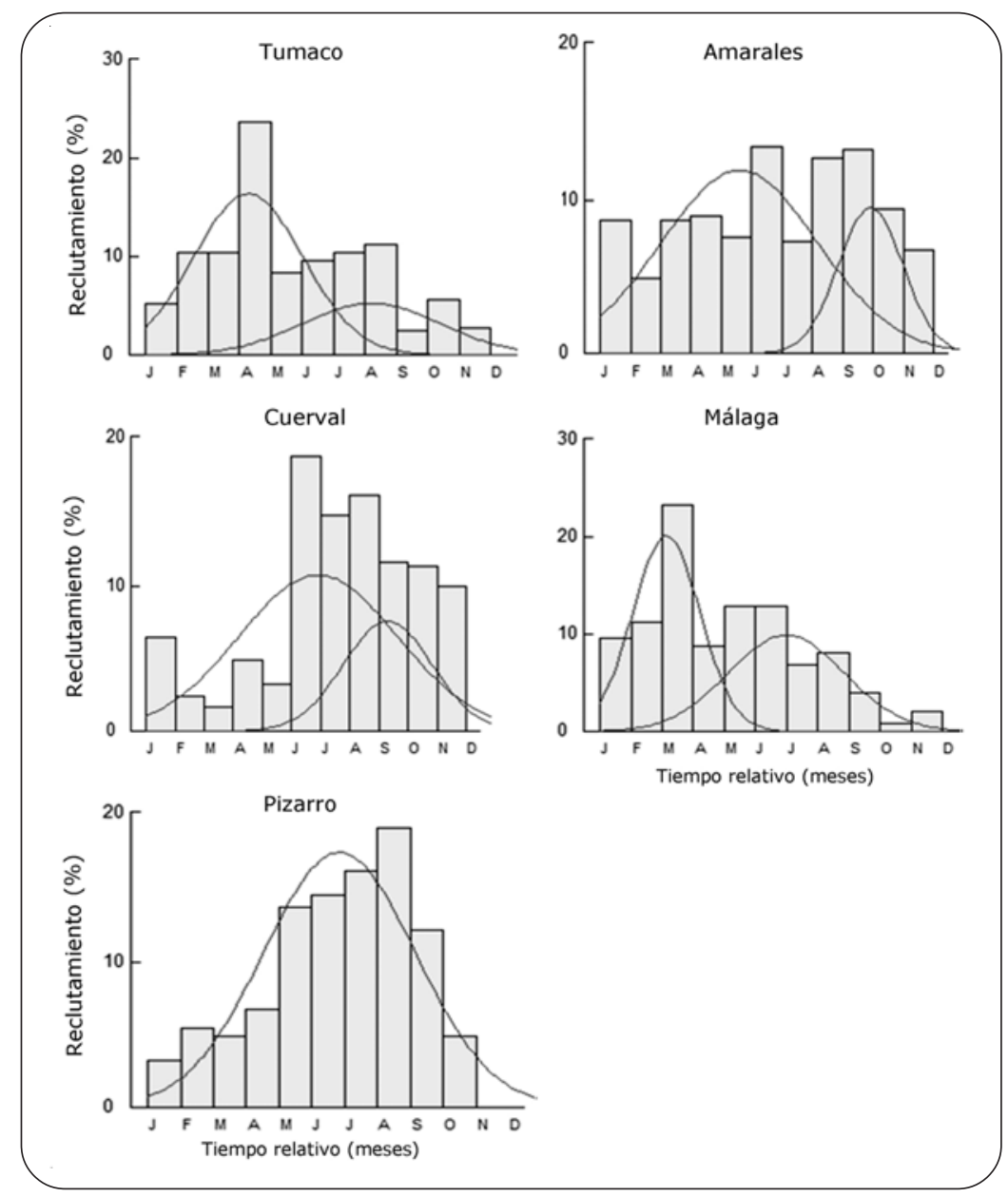

Figura 6. Patrón de reclutamiento anual de Anadara tuberculosa en la costa Pacífica colombiana en 2009 y $\mathbf{2 0 1 0}$ / Annual recruitment pattern of Anadara tuberculosa in the Pacific coast of Colombia in 2009 and 2010

estrategias de manejo pesquero, como en el caso de vedas, para poder proteger la población sexualmente madura y desovante.

Los individuos con mayor actividad sexual se encontraron en Tumaco y Cuerval, lo cual puede generar alta presencia de estados larvales y reclutamientos en todo el año. Los resultados muestran que existen variaciones en las épocas de maduración sexual con respecto a otras áreas del Pacífico americano difiriendo con lo encontrado por Cruz (1982) y (1984) en Costa Rica, pero se concuerda con algunos registros a nivel local especialmente en la temporada reproductiva del primer semestre del año, tal como lo mencionan (Herrán 1983, Cruz 2004, Lucero \& Cantera 2008). Herrán (1984) encontró en la bahía de Buenaventura (Punta Soldado), que las principales épocas de madurez sexual son en febrero (máximo pico), abril, septiembre y diciembre,
Lucero et al. (2012), encontraron en bahía Málaga gran actividad reproductiva en abril y diciembre. Borda \& Cruz (2004a) en la Ensenada de Tumaco, determinaron 2 picos de reproducción, en noviembre y febrero, lo que coincide con lo expuesto por Squires et al. (1975) en Colombia y Cruz (1982) en Costa Rica. Las diferencias se podrían relacionar con variaciones ambientales como la temperatura y pluviosidad (Kusakabe 1959, Pathansali 1961, Campos et al. 1990) y con la salinidad (Cruz 1987).

Los registros anteriores muestran que la evaluación de la actividad reproductiva en varias localidades del Pacífico colombiano y de forma simultánea para esta especie, no había sido estudiada aun y la información es fragmentada en el tiempo y en el espacio, por lo tanto, su registro es ausente en Colombia y escasos en el resto del Pacífico americano. 
En Tumaco, Málaga, Pizarro y Amarales, el rendimiento de la carne, presenta un comportamiento similar a la maduración sexual de $A$. tuberculosa, lo cual sugiere que el aumento de carne es un buen indicador de los eventos reproductivos para esta especie, así lo demuestra también Silva \& Bonilla (2001), Cruz \& Palacios (1983). El rendimiento, también es un indicador de la calidad del ambiente en que vive este recurso, ya que la producción de carne está relacionada con la precipitación, el aumento de materia orgánica y disposición de nutrientes en las aéreas de manglar (Cruz \& Palacio 1983 y Silva \& Bonilla 2001). Cruz (1982), también encontró en Costa Rica, una relación con las condiciones ambientales como la pluviosidad, en donde los meses secos presentan valores bajos del índice de condición.

Los individuos de mayor peso total, menor rendimiento y mayor talla de madurez, se encuentran en Pizarro y Amarales, donde existe menor explotación de este recurso, mientras que los de mayor peso de carne menor talla de madurez y mayor rendimiento son de Tumaco donde hay mayor explotación. Esto podría indicar que en áreas de baja explotación, los individuos tienden a aumentar más en talla y espesor de la concha que de carne, lo cual estaría mostrando ejemplares de mayor edad. Anadara tuberculosa presenta un mayor incremento de carne hasta la talla de $40 \mathrm{~mm}$, a partir del cual su rendimiento en carne disminuye pero el aumento de peso total no, ya que crece más en concha por incorporación de carbonato de calcio. Resultados similares fueron encontrados por Cruz \& Palacio (1983) y Silva \& Bonilla (2001). Esto indica la calidad del producto con fines comerciales, ya que las comunidades locales en el Pacífico colombiano, obtienen mejores utilidades en peso de carne con individuos de tallas menores.

Los resultados indican que $A$. tuberculosa puede iniciar su actividad reproductiva a los 20,18 $\mathrm{mm}$ de longitud, mostrando un inicio reproductivo más temprano en Tumaco donde existe la mayor presión de pesca en Colombia, y prolongando el inicio sexual de su vida en áreas donde existe una baja dependencia del mismo como Pizarro y Amarales, esta última ubicada dentro del área del Parque Nacional Natural Sanquianga, lo cual permite un mejor manejo y control de la pesca.

Se encontró que $A$. tuberculosa inicia su madurez sexual en rangos reportados en otros estudios para el Pacífico americano, Ampie \& Cruz (1989) (23,20 mm y 26,20 $\mathrm{mm}$ ) en Costa Rica; Borda \& Cruz (2004 $)$ (25 mm) en Tumaco. Sin embargo, Lucero et al. (2012), reportan el inicio de madurez sexual de esta especie en bahía Málaga en 18,87 mm, lo cual está por debajo de la talla encontrada en este estudio, mostrando cierta precocidad sexual. Estas tallas pueden ser consideradas como el inicio de la sexualidad de A. tuberculosa, teniendo en cuenta que en otras especies del genero Anadara, las gónadas se pueden diferenciar a partir de los $12 \mathrm{~mm}$ de talla, y el primer desove toma lugar a los $20 \mathrm{~mm}$ de longitud (Afiati 2007). Las hembras de esta especie, son generalmente de mayor talla y abundancia que los machos, mostrando una relación de sexos durante el periodo de estudio de 2,46:1 (Hembra: Macho), otros estudios también muestran mayor presencia de hembras, Flores \& Lincadeo 2010 en Ecuador (2,57:1) y Lucero et al. (2012) en Colombia (1,6:1), sin embargo, difiere de otros estudios para esta misma especie (Cruz 1984a, Silva \& Bonilla 2001, Pérez-Medina 2005) quienes encontraron una proporción 1:1. En otras especies de Anadara, también se reporta mayor abundancia de hembras, Yankson (1982), Mzighani (2005) y Afiati (2007).

Afiati (2001), indica que las hembras son más abundantes solo en tallas superiores a $35 \mathrm{~mm}$. Esta condición, sugiere procesos de reversión sexual de machos a hembras, lo cual es considerado común en los bivalvos (Mzighani 2005). En el Pacífico americano, solo PérezMedina (2005), reportó un 0,98\% de hermafroditismo en Santo Domingo, México para A. tuberculosa, pero fue considerado casual debido a la escasez de hallazgos. En el presente estudio, se encontró una mayor abundancia de hembras, las cuales fueron generalmente de mayor talla que los machos y con 3,1\% de hermafroditas de un total de 290 individuos analizados, porcentaje de hermafroditas que aún no ha sido registrado en la literatura para esta especie. Se encontró hermafroditismo en todas las localidades estudiadas en el Pacífico colombiano, considerando a Anadara tuberculosa una especie hermafrodita protándrica, debido a las diferencias en la proporción sexual (Afiati 2007, Flores \& Lincadeo 2010), presencia de tallas menores de machos con respecto a las hembras y a la presencia de espermatozoides y óvulos funcionales en el mismo individuo. Debido al porcentaje de hermafroditismo reportado en este estudio, se considera que este no es casual, y que por el contrario puede ser una condición natural de esta especie en el Pacífico colombiano.

La talla media de primera madurez encontrada para el Pacífico colombiano (43,5 mm), se encuentra dentro del rango reportado por Borda \& Cruz (2004a) (44 mm) en Tumaco y Aguilar et al. (1999¹) (43 mm) en Perú, pero es superior a lo registrado por otros autores como Herrán 
(1984) para Buenaventura (39 mm) y Lucero et al. (2012) en Bahía Málaga (39,50 mm). Lucero \& Cantera (2008), encontraron una talla media de 47,21 mm en Cuerval (Cauca), lo cual es superior al promedio reportado en este estudio para toda la región Pacífica. No obstante, aunque los estudios anteriores, muestran una tendencia importante de las variaciones en las tallas de madurez, son de carácter puntual en la escala espacial. Esta investigación realizada en una escala espacial mayor, soporta la estimación de la talla mínima legal de captura de $50 \mathrm{~mm}$ estipulada por la ley de Colombia, ya que por debajo de esta medida, las capturas estarían disminuyendo el potencial reproductivo de las poblaciones de piangua.

Se presentaron reclutamientos durante todo el año, pero a mediados del primer semestre y comienzos del segundo, se registran los mayores procesos para las zonas de manglar. Este reclutamiento, se relaciona con los desoves en cada región, ya que después de la fecundación, los individuos tardan aproximadamente de 1 a 3 meses para reclutarse. Las semillas, suelen permanecer adheridos a una concha o ser arrastrados por las corrientes cuando están fijados a troncos de árboles y restos de fibra de coco en las zonas sumergidas de bahías y ensenadas, en donde la pesca del camarón es importante. Squires et al. (1975), también indica que post-larvas de piangua entre 1-2 $\mathrm{mm}$, son encontradas en zonas sumergidas, especialmente a profundidades de 3-5 m en la Bahía de Buenaventura. Tanto las épocas de reproducción como de reclutamiento, coinciden con la temporada de lluvias en los primeros meses del año y a mitad del mismo. Así por ejemplo en la zona sur del Pacífico colombiano, Tumaco, Amarales y Cuerval, los mayores picos de reclutamientos coinciden con la temporada de lluvias históricas entre enero a junio, mientras que en la zona norte (Pizarro) con la segunda temporada de lluvia más intensa en la región (de septiembre a noviembre).

En conclusión, el comportamiento bimodal y la similitud de los meses con mayor presencia de reclutas se presentó en la región central y sur del Pacífico colombiano (Bahía Málaga, Tumaco, Amarales y Cuerval). Esto es consecuencia de la mayor actividad reproductiva que se registra en estas zonas, Estos resultados no coinciden con lo expuesto por Borda \& Cruz (2004a), quienes encontraron en Tumaco que el ciclo estacional de los juveniles es muy variable, pero con periodos de máximo reclutamiento en mayo, agosto y diciembre. Estas diferencias están determinadas por la variación de condiciones climáticas cada año, eventos oceanográficos de gran escala y las corrientes. Debido a la característica planctónica de la larva (Borda \& Cruz 2004a), su distribución está regulada por las corrientes marinas. La corriente costera de Colombia, que fluye en sentido Nor-noreste, puede tener un gran impacto en la distribución de las especies de Anadara en la región central y sur del Pacífico colombiano, así como la corriente costera del Chocó que fluye hacia el sur y podría influenciar la distribución de pianguas en la parte norte del Pacífico. Estos patrones de corrientes en relación con la distribución de las especies de Anadara, deben ser estudiados en la costa Pacífica de Colombia. En Pizarro y Amarales, donde hay menor actividad reproductiva, el reclutamiento anual se sostiene por los desoves de áreas adyacentes como Tumaco y Cuerval al sur y Catripe, Docampadó y Nuquí al norte del Pacífico colombiano. No obstante, puede existir una influencia de la densidad poblacional en los procesos de reclutamientos en la zona evaluada, ya que el reclutamiento local puede ser limitado por la biomasa del stock parental establecido, es decir hay una inhibición del reclutamiento a altas densidades de adultos (Caddy \& Defeo 2003).

Este estudio es el primer análisis simultáneo de la actividad reproductiva en varias regiones costeras, constituyéndose en una base importante para el manejo de esta especie, fue el primero en abordar la biología reproductiva de $A$. tuberculosa en una amplia escala espacial en todo el Pacífico colombiano, brindando un mejor entendimiento con miras a plantear acciones de manejo adicional que permitan el aprovechamiento pesquero sostenible de la especie. La asincronía sexual encontrada demuestra que algunas de estas acciones deben ser consideradas a escalas locales, por lo que acciones como vedas, en amplias regiones no serían recomendables.

\section{Agradecimientos}

Los autores desean expresar su muy especial gratitud a las instituciones que permitieron ejecutar este proyecto como INVEMAR, Universidad del Valle, UAESPNN Sanquianga, WWF Colombia y ASCONAR, como también

\footnotetext{
${ }^{1}$ Aguilar S, G Castillo, M Soto \& C Luque. 2003. Algunos aspectos biológicos del recurso concha negra (Anadara tuberculosa) en el Litoral Norte del Perú durante 1999.Informe, Departamento de Biología, Facultad de Ciencias Biológicas, Universidad Nacional Mayor de San Marcos.
} 
a las poblaciones del Pacífico colombiano que ayudaron a la realización de este trabajo, especialmente a Carmen Julia Palacios, Juan Eugenio Jiménez, Luis Carlos Lleras, Comunidad de la Plata (Bahía Málaga), Comunidad de ‘El bajito’, Tumaco, Amarales, el Consejo Comunitario de Cuerval-Timbiquí y los Consejos Comunitarios del Cauca (Cococauca). El presente trabajo fue realizado en el marco del proyecto 'Potencial productivo de las poblaciones naturales de la piangua Anadara tuberculosa y Anadara similis dentro de una perspectiva espaciotemporal en la costa Pacífica colombiana', financiado por el Ministerio de Agricultura y Desarrollo Rural de Colombia (contrato 161-2008T-3459) y con el apoyo del BPIN PNIBM (años 2008 y 2009) y BEM (2010) y el Banco de Inversión de proyectos-BPIN Resolución 0085 del 6 de febrero de 2013.

\section{LITERATURA CITADA}

Afiati N. 2007. Hermaphroditism in Anadara granosa (L.) and Anadara antiquata (L.) (Bivalvia: Arcidae) from central Java. Journal of Coastal Development 10: 171-179.

Alamo V \& Valdivieso V. 1997. Lista sistemática de moluscos marinos del Perú. Segunda edición, revisada y actualizada. Boletín del Instituto del Mar del Perú, Vol. Extr: 1-183.

Ampie CL \& RA Cruz 1989. Tamaño y madurez sexual de Anadara tuberculosa (Bivalvia:Arcidae) en Costa Rica. Brenesia 31: 21-24.

Baqueiro EC. 1984. Status of molluscan aquaculture on the Pacific coast of Mexico. Aquaculture 39: 83-93.

Baqueiro E \& J Stuardo. 1977. Observaciones sobre la biología, ecología, ecología y explotación de Megapitaria aurantiaca (Sow., 1831) M. squalida (Sow., 1835) y Dosinia ponderosa (Gray, 1838) (Bivalvia; Veneridae) de la Bahía de Zihuatanejo e isla Ixtapa, Gro., México. Anales del Centro de Ciencias del Mar y Limnología, Universidad Nacional Autónoma de México 4: 161-208.

Betancourth J \& J Cantera. 1978. Estudio ecológico y económico de la piangua. Memorias Primer Seminario sobre el Océano Pacífico sudamericano, Cali, 6 pp.

Borda CA \& R Cruz. 2004a. Reproducción y reclutamiento del molusco Anadara tuberculosa (Sowerby, 1833) en el Pacífico colombiano. Revista de Investigaciones Marinas 25: 185-195.<http://www.cim.uh.cu/rim/pdf/2004/3/2004185.PDF>

Borda CA \& R Cruz. 2004b. Crecimiento y tasas de mortalidad del bivalvo Anadara tuberculosa (Sowerby, 1833) en el Pacífico colombiano. Revista de Investigaciones Marinas 25: 177-184.

Borda CA \& R Cruz. 2004c. Pesca artesanal de bivalvos Anadara tuberculosa y A. similis y su relación con eventos ambientales, Pacífico colombiano. Revista de Investigaciones Marinas 25: 197-208.
Broom MJ. 1982. Structure and seasonality in a Malaysian mudflat community. Estuarine, Coastal and Shelf Science 15: 135-150.

Broom MJ. 1985. The biology and culture of marine bivalve mollusks of the genus Anadara. ICLARM Studies and Reviews 12, Contribution 263: 1-37.

Caddy JF \& O Defeo. 2003. Enhancing or restoring the productivity of natural populations of shellfish and other marine invertebrate resources. FAO Fisheries Technical Paper 448: 1-159.

Campos J, ML Fournier \& R Soto. 1990. Estimación de la población de Anadara tuberculosa (Bivalvia: Arcidae) en Sierpe-Terraba, Costa Rica. Revista de Biología Tropical. 38: 477-480.

Cantera JR \& R Contreras. 1978. Informe preliminar sobre el potencial malacológico aprovechable en el Pacífico colombiano. Memorias. I. Seminario de Oceanografia del. Pacífico Sudamericano 2: 440-474.

Cruz RA. 1982. Variación mensual del índice de condición del molusco Anadara tuberculosa (Pelecypoda: Arcidae) en punta Morales. Puntarenas Costa Rica. Revista de Biología Tropical 30: 1-4.

Cruz RA. 1984. Algunos aspectos de la reproducción en Anadara tuberculosa (Pelecypoda: Arcidae) de Punta Morales, Puntarenas, Costa Rica. Revista de Biología Tropical 32: 45-50.

Cruz RA. 1987. The reproductive cycle of the mangrove cockle Anadara grandis (Bivalvia: Arcidae) in Costa Rica. Brenesia 27: 1-8.

Cruz RA \& JA Palacios. 1983. Biometría del molusco Anadara tuberculosa (Pelecypoda: Arcidae) en Punta Morales, Puntarenas, Costa Rica. Revista de Biología Tropical 31: 175-179.

Cruz R \& CA Borda. 2003. Estado de explotación y pronóstico de la pesquería de la piangua Anadara tuberculosa (Sowerby, 1833) en el Pacífico colombiano. Revista de Investigaciones Marinas 24: 221-230.

Espinosa S, MF Delgado, B Orobio, LM Mejía Ladino, DL Gil-Agudelo. 2010. Estado de la población y valoración de algunas estrategias de conservación del recurso piangua Anadara tuberculosa (Sowerby) en sectores de Bazán y Nerete, costa Pacífica nariñense de Colombia. Boletín de Investigaciones Marinas y Costeras 39: 161-176.

Flores L \& R Lincadeo. 2010. Size composition and sex ratio of Anadara tuberculosa and Anadara similis in a mangrove reserve from the northwest of Ecuador. Revista de Biología Marina y Oceanografía 45: 541-546.

Fournier ML \& E De La Cruz. 1987. Reproduction of the cockle Anadara grandis in Costa Rica. Naga 10: 6.

Franco L. 1995. Uso y conservación de moluscos del Género Anadara (Mollusca: Bivalvia): Evidencia poblacional en un gradiente de explotación humana en el Chocó, Costa pacífica colombiana. Tesis de Maestría, Facultad de Ciencias Naturales y Exactas, Universidad del Valle, Cali, 139 pp. 
García-Domínguez FA, A De Haro Hernández, A García Cuellar, M Villalejo-Fuerte \& S Rodríguez-Astudillo. 2008. Ciclo reproductivo de Anadara tuberculosa (Sowerby, 1833) (Arcidae) en Bahía Magdalena, México. Revista de Biología Marina y Oceanografía 43: 143-152.

Gayanilo FC Jr, P Sparre \& D Pauly. 2005. The FAO ICLARM Stock Assessment Tools (FiSAT II) User's Guide. FAO, Computerized Information Series (Fisheries) 8. <http://www.ccs.miami.edu/ fgayanilo/documents/ Gayanilo_Pub_05a_part.pdf>

Gil-Agudelo DL, S Espinosa, MF Delgado, W Gualteros \& CH Lucero. 2011. La pesquería tradicional de piangua el Pacífico colombiano, entre la subsistencia y el comercio. En: Diaz JM, C Vieira \& G Melo (eds). Diagnóstico de las principales pesquerías del Pacífico, pp. 49-79. Fundación Marviva-Colombia, Bogotá

Haskoning CN. 1986. The impact of channel improvement works on mangroves and associated piangua fishery in Colombia, 200 pp. Corporación Autónoma Regional del Valle del Cauca, Cali.

Herrán Y. 1983. Observaciones sobre el desarrollo gonadal de la 'piangua' Anadara tuberculosa y Anadara similis en Punta Soldado, Bahía de Buenaventura. Tesis de pregrado. Facultad de Ciencias Naturales y Exactas, Universidad del Valle, Cali, 110 pp.

JICA-CENDEPESCA. 2007. Guía para la producción de Anadara spp. 2006-2007. Producción artificial de semillas, cultivo intermedio y cultivo de Anadara tuberculosa y Anadara grandis, 80 pp. Agencia Internacional de Cooperación del Japón / Centro de Desarrollo de la Pesca y Acuicultura, San Salvador. <http://www.jica.go.jp/project/ elsalvador/22 $71029 \mathrm{E} 1 / \mathrm{m}$ aterials/pdf/ 2007 / 2007_01_01.pdf>

Jiménez GE. 1988. Bioestadística, 441 pp. Universidad Santo Tomás, Bogotá.

Kenneth VL Jr. 1969. Seasonal gonadal changes in two bivalve mollusks in Tomales Bay, California. The Veliger 11(4): 382-390.

Kusakabe D. 1959. Studies on the culture of the artificial seeds of the ark shell Anadara subcrenata (Lischke). Journal of the Faculty of Applied Biological Science, Hiroshima University 2: 183-259.

Lucero CH \& JR Cantera. 2008. Análisis de la explotación de la piangua hembra Anadara tuberculosa en El Consejo Comunitario de Cuerval-Cauca, Pacífico colombiano. Informe Técnico, Consejo Comunitario de Cuerval, GuapiCauca, pp. 1-28.
Lucero CH, J Cantera \& R Neira. 2012. Pesquería y crecimiento de la piangua (Arcoida: Arcidae) Anadara tuberculosa en la Bahía de Málaga del Pacífico colombiano, 2005-2007. Revista de Biología Tropical 60: 203-217.

Mzighani S. 2005. Fecundity and population structure of cockles, Anadara antiquata L. 1758 (Bivalvia: Arcidae) from a sandy/muddy beach near Dar es Salaam, Tanzania. Western Indian Ocean Journal of Marine Science 3: 221-225.

Narchi W. 1976. Ciclo anual da gametogenese de Anomalocardia brasiliana (Gmelin, 1791) (Mollusca Bivalvia). Boletim de Zoologia da Universidade de São Paulo 1: 331-350.

Pathansali D. 1961. Notes on the ecology of the cockle Anadara granosa. L. Proceedings, Indo-Pacific Fisheries Council 11: 84-98.

Pérez-Medina DR. 2005. Biología reproductiva de Anadara tuberculosa (Bivalvia: Arcidae) en el estero Santo Domingo. B. C. S., México. M. Sc. Tesis, Instituto Politécnico Nacional, Centro Interdisciplinario de Ciencias Marinas, La Paz, 71 pp.

Ortiz E, E Uria, A Silva Olivares, V Tsutsumi \& M Shibayama. 2003. Estudio de la ultraestructura de la espermatogénesis de Anadara tuberculosa (Sowerby 1833) (Mollusca: Pelecypoda: Arcidae). Hidrobiológica 132: 145150.

Roldan AM, MF Delgado, LA Zapata, C Candelo, CJ Palacios, W Gualteros, C Lucero, S Espinosa, OF Muñoz, GA Mayor \& DL Gil-Agudelo. 2010. El establecimiento de acuerdos de comanejo del recurso piangua (Anadara tuberculosa) en la costa Pacífica colombiana, una oportunidad para su conservación. En: INVEMARACIMAR (eds). Libro de Resúmenes extendidos XIV Seminario de Ciencias y Tecnologías del Mar, SENALMAR. Serie de Publicaciones Especiales, INVEMAR. 21: 411416.

Silva BAM \& R Bonilla. 2001. Abundancia y morfometría de Anadara tuberculosa y A. similis (Mollusca: Bivalvia) en el manglar de Purruja, Golfo Dulce, Costa Rica. Revista de Biología Tropical 49: 315-320.

Squires HG, M Estevez, O Barona \& O Mora. 1975. Mangrove cockles, Anadara spp. (Mollusca: Bivalvia) of the Pacific coast of Colombia. Veliger 18(1): 57-68.

Tresierra AAE \& EZG Culquichicon. 1995. Manual de biología pesquera, 227 pp. CONCYTEC, Trujillo.

Yankson K. 1982. Gonad maturation and sexuality in the West African bloody cockle Anadara senilis (L). Journal of Molluscan Studies 48: 294-300.

Zar J. 1999. Biostatistical analysis, 716 pp. Prentice Hall, Englewood Cliffs.

Recibido el 20 de septiembre de 2012 y aceptado el 10 de junio de 2013

Editor: Claudia Bustos D. 